\title{
Discussion on the Combination of "Double Reduction" Policy and Ideological and Political Education
}

\author{
Yuanyuan Xu \\ School of Marxism, Hainan University, Haikou, China \\ thisisxyy@163.com
}

\begin{abstract}
The "double reduction" policy and ideological and political education are highly compatible. The implementation of the "double reduction" policy needs the support of ideological and political education, and it is also an important background, precious subject matter and vivid example for ideological and political education in the new era. The combination of the two is aimed at primary and secondary school students, their parents, primary and secondary school educators, and other members of society. It focuses on the concepts of learning, education, career, and labor. On the basis of understanding "why the two can be combined", this paper grasps "for whom to combine" and keeps exploring "how to combine", so that the two can promote and complement each other.
\end{abstract}

Keywords: Double Reduction; Ideological and Political Education; Compulsory Education.

\section{The Highly Compatibility of "Double Reduction" Policy and Ideological and Political Education}

\subsection{The Dilemma Faced by the Implementation of the "Double Reduction" Policy}

The implementation of the "double reduction" policy has impacted on the traditional educational concepts in China. Due to the tradition of "literati ruling the country" since ancient times, high school and college entrance examinations play a pivotal role in social mobility, just like the ancient imperial exams, so that many problems and conflicts are attributed to people's own lack of education. Due to the limited educational resources, the competition for educational resources has become quite common. Attending education courses has become an important means for people to compete for education resources, and the education industry has thus been growing with the expansion of the market.

Such concept is deeply rooted in people's minds. Although previous attempts have been made across the country to implement such stress-reducing and corrective measures, they have not been widely promoted, nor have they had such great compelling power and influence. The introduction of the "double reduction" policy attempts to cut off people's over-reliance on the education and training industry, promote educational equity, reduce the burden for the public and reduce vicious competition, but also with people's thinking and action inertia. Therefore, while the "double reduction" policy has gained support, it has also met with discontent and opposition, with some people - especially those directly related to it, such as parents of primary and secondary school students, educators expressing their discontent or opposition.

As a result, the problem of perception lead to problems of practice. Some people do not cooperate with the implementation of the policy, "exploit the loopholes" before the concrete and strict implementation of the policy, "work in grey" by seeking various means to avoid the reform, which are disguised as a violation of the policy provisions. This is contrary to the original intent of the policy, impede the further implementation of the policy. It is clear that the "double reduction" policy is in the initial implementation of the pain period. It is necessary to actively address the problem in order to improve the effectiveness of the policy and to fundamentally solve the uncontrolled increase in the academic burden of students in mandatory education [1].

\subsection{Characteristics and Demands of Ideological and Political Education in the New Era}

With the development of the times, people are becoming more open-minded and inclusive. Ideological and political education further deepens and presents new trends and characteristics. 
Traditional text-based and purely theoretical ideological and political education can no longer meet the practical needs, and it is easy to make students burn out. On more occasions, those flexible, vivid, targeted and diversified educational contents and forms are more effective than the former. At the same time, the ideological struggle in the new era is more intense and hidden than before, and ideological and political education also penetrates into every aspect of people's lives and every moment, which has a subtle effect on people's thoughts and behaviors. So, ideological and political education must be strengthened and optimized in details. In addition, ideological and political education always serves the specific era and is carried out in it, and it is detached from the issues of the era lacks vitality and relevance.

Therefore, in the new era, ideological and political education is put forward with higher requirements. Ideological and political educators should circumvent the theoretical indoctrination, link theory to practice, integrate ideological and political education into life, and grasp every suitable moment to combine or use current hotspots and examples to provide more vivid education. This can not only enhance the enthusiasm and subjectivity of the educated, but also achieve the purpose of education deeply and efficiently. It can also make ideological and political education return to reality and enhance its modernity. It will be better accepted and people's prejudice that it is "pavilions in the air" would also be challenged.

\subsection{The Fit between the "Double Reduction" Policy and Ideological and Political Education}

As mentioned above, the "double reduction" policy and ideological and political education are highly compatible to each other. Ideological and political education can help the "double reduction" policy to get rid of the difficulties of implementation from the level of ideology. Its implementation is an important background, precious subject matter and an vivid example.

First of all, the implementation of the "double reduction" policy needs the assistance of ideological and political education. At the beginning of the implementation of the policy, its actual effectiveness has not really played, and is highly controversial. contradicted views are a major reason for the dissipation of the effectiveness of the policy, leading to violation of policy provisions. This requires the use of ideological and political education to fundamentally solve, otherwise it will lead to inefficient policies and waste of resources.

Secondly, the ideological and political education in the new era can be optimized and enriched by the "double reduction" policy. At present, "double reduction" is in full swing, which is a good opportunity and material for ideological and political education. Ideological and political educators can analyze the ideological problems behind the "double reduction", carry out ideological guidance in the context, guide people to establish correct concepts and form a good social climate. The "double reduction" can also be used as educational material to explore the profound educational connotation.

The real implementation of the policy requires the simultaneous development of ideological and political education. Ideological and political education needs to be carried out in the context of the times, and its content needs to be enriched and improved by adding contemporary themes. The combination of "double reduction" policy and ideological and political education not only adapts to people's cognitive characteristics, but also meets the development demands of ideological and political education.

\section{The Target of "Double Reduction" Policy and Ideological and Political Education}

\subsection{Primary and Secondary School Students and Their Parents}

Primary and secondary school students and their parents are one of the groups most related to the "double reduction" policy. They play a major role in the process of policy implementation, and their feedback also has a social influence that cannot be ignored. 
Volume 14 (2021)

Many parents do not understand the essence of the policy and complain that the policy will not solve the problem of educational equity and will even lead to more serious educational imbalance. They put themselves in the role of "victims" and are indifferent to and strongly criticize the policy both online and in real life, which affects the smooth implementation of the policy. Some parents, imprisoned by traditional education concepts, are obsessed with higher education and do not want their children to lag behind, so they are anxious and try to find countermeasures (such as finding oneto-one tutors, sending their children to private schools). But this increases mental burden of the family and deviates from the original purpose of the policy to "reduce the burden".

\subsection{Elementary and Secondary School Educators}

Elementary and secondary school educators are also directly affected by the "double reduction" policy, including both on-campus and off-campus ones.

On the one hand, off-campus educators are facing unemployment and enormous pressure to find jobs, and they are in a state of frustration and confusion for a certain period of time. For this reason, some teachers and trainers open off-campus workshops or use other forms to cover up informal feebased training to avoid review and rectification. On the other hand, on-campus teachers in schools are also required to improve the quality of education and overwork to provide better services to students. The increasing working pressure ultimately brings about discontent and dissatisfaction with the policy.

\subsection{Other Social Members}

Primary and secondary school students and their parents, as well as primary and secondary school educators, are the groups directly related to the "double reduction" policy, while other members of society are also inextricably linked to it. The public debate over the "double reduction" policy reflects that there are still many people in the society who do not speak highly of it. Like some of the students, parents, and educators of primary and secondary school students mentioned above, some people doubt the feasibility of the "double reduction" policy and the government's ability to implement it, and even claims that it does more harm than good.

The spread of such views in reality and on the Internet can, to a certain extent, hinder the formation of a good social climate, affecting not only the perceptions and behaviors of groups directly related to the policy, but also the lives of every member in the society. Whether these views are wellintentioned or malicious, behind people's lack of understanding of national policies are conceptual problems that need to be solved through ideological and political education. One of them is to break the traditional concept, and the other is to make people understand, believe and support the national decision.

\section{How to Combine the "Double Reduction" Policy with Ideological and Political Education}

\subsection{For Primary and Secondary School Students and Their Parents}

(1) Scientific view of learning

Traditional education tends to make people fall into the misconception of "having regular class is not enough", which is also an important reason for the high academic pressure of primary and secondary school students in general. The "double reduction" policy is dedicated to reducing the academic burden of students in compulsory education, which first requires a correct perception of learning.

Students and parents should understand that the initiative and ownership of learning lies with the individual. There is no decisive correlation between academic performance and whether or not extracurricular training is provided. The school classroom is the main classroom, which can provide sufficient educational resources and learning opportunities. Especially after the "double reduction" 
policy has clearly proposed to expand the quality of compulsory education resources, improve the quality of classroom teaching, after-school services and other initiatives, the school will be able to play a better role as the main position. Parents should guide their children to learn to use resources and seize opportunities, and not to put the cart before the horse and pin their academic success on extracurricular training and other "auxiliary means". The most important thing is developing good habits of independent learning, finding a suitable learning method and take the lead in learning.

(2) The new era's view of education

Test-based education has always been the main mode of education in China, which has led many parents to pursue academic achievement unilaterally and to focus only on intellectual education, while neglecting other aspects of training. In the new era, the society has attached more and more importance to quality education and comprehensive development, and fully stimulating students' talents has become an important goal of talent training.

The "double reduction" policy proposes to "deepen the reform of high school enrollment", build a diversified evaluation system, and create multiple talent choices [2]. It puts the overall quality of students in a prominent position. This suggests that parents should pay attention to the comprehensive quality of their children's training, and avoid the pursuit of test scores. Parents should carefully observe where their children's interests and talents lie, teach them according to their abilities, and give full play to their children's strengths beyond test-based learning in order to allow them to develop in a balanced and healthy way. It should be clear that it is not that enrolling in more classes or accompanying more lessons is doing one's duty. Parents should overcome the myopia of education [3] and truly participate in the cause of nurturing the overall development of moral, intellectual, physical, social and aesthetic development.

(3) Good vocational and labor concept

The deeper reason why many parents do not support the "double reduction" policy is related to the concept of career and labor. They think that this policy reduces the possibility of their children getting higher education and increases the "risk" of their children entering vocational high school and going to blue-collar career, and directly link this "risk" to their future happiness.

In recent years, the state has been vigorously developing vocational education, issuing and implementing documents such as "Opinions on Promoting the High-Quality Development of Modern Vocational Education". In addition, it has achieved good results in improving the treatment of skilled workers, and has created a good atmosphere of "labor pride" in the whole society. The status of workers in society has been significantly improved. At the same time, the state has always supported the sustainable and healthy development of the real economy, which requires students of higher education and high schools to cultivate a good work ethic and craftsmanship, and join the grassroots skill positions to provide strong talents and skill support for the comprehensive construction of a modern socialist country. As long as they are practical and diligent, they can become talents in a certain field and have a sense of professional success and achievement.

Therefore, parents should set role models for their children, take the lead in avoiding utilitarian orientation, establish a good view of career and labor, improve their personality, and enhance their social adaptability [4].

(4) Correct interest values

The concept of career and labor is born out of the concept of interest. Similar to the problems caused by career and labor views, the difference of interest view is the root cause of the different views on the "double reduction" policy. Today's society is a highly developed market economy, and people's pursuit of interests is reinforced by the market's reverence for interests [5]. As a result, the influence of the concept of interest on people's lives is particularly prominent, and the existence of a biased concept of interest often leads to vicious competition, which is not conducive to personal and social development.

The outlook on life is the guide to grasp the direction of life and choose the path of life, guiding the attitude of people and the choice of life values [6]. A narrow view of life will lead people into the 
contradiction between reality and expectation, and put them in a state of anxiety. An open view of life will make people content, which is the secret of a happy life.

Therefore, parents must work with their children to correct their view of interests, prevent the pursuit of fame and profit, and abandon the concept that good education, good job, high salary, and high status are the only things they want, so that they can better understand and accept the "double reduction" policy and reduce the negative factors for their children's healthy physical and mental growth in terms of concepts and behaviors.

Society needs people with different strengths and levels to perform their respective roles. Students and parents need to find their own position, determine their own goals according to the actual situation, and not overly demand achievements that are not in line with their own conditions. In the context of the "double reduction" policy, it is necessary to pursue upward development, but too much is too little, do not overly pursue beautiful results, glamorous careers, and for this reason cling to extracurricular training, trapping themselves and others in a situation of internalization. Only by developing a positive outlook and mindset can individuals and society achieve sustainable, healthy development.

\subsection{For Primary and Secondary School Student Educators}

(1) Love the Job and Dedication

Whether the teacher is working on-campus or off-campus, he needs to correct the professional attitude first. The core of the education industry is "education", not utilitarianism. The "double reduction" policy, all utilitarian or capital-oriented extracurricular training behavior will be outlawed. Educators must return to their hearts, focus on "education" itself, obey the policy, and make their professional behavior legitimate; at the same time, they must uphold the spirit of love and dedication, and enthusiastically devote themselves to education in order to realize their essential value as "teachers".

(2) Pursue Progress and Improve Skills

Improving skills is an effective way for educators to meet the challenges posed by the "double reduction" policy. The introduction of the "double reduction" policy will make the competition for each position more intense, which will force educators to improve their skills, and enhance their quality. And this is one of the purposes of the "double reduction" policy.

Under the strict restriction of the education department, most of the off-campus educators are at risk of losing their jobs. Some of the negative and pessimistic ones stumble after the setback and are eventually abandoned by the torrent of the times. The upward ones rise to the challenge and actively engage in the examination for teacher preparation or change of career. This requires the teaching and training staff to change their mentality, enhance the learning and exercise of professional skills, and stand firm in the fierce employment competition as soon as possible.

On-campus teachers are also under pressure to improve teaching quality and need to adjust their mindset to improve and not rest on their laurels.

(3) Other Social Members

According to Pierre Bourdieu's theory of habituation, habituation will lead actors to choose the way of behavior that is most likely to succeed based on their resources and past experiences. This "habit" often manifests itself in the form of traditional ideas in society. Traditional culture gives rise to traditional educational concepts, which are internalized in more general psychological tendencies, such as reliance on extracurricular training and the preference for higher education, and it is these tendencies that guide people's actions.

When the concept is not suitable for the real situation, it should be renewed by the time. The reformation of the concept of the members of the society itself is conducive to the renewal of the social atmosphere and the development of the society. Moreover, the changes made in the social atmosphere from the view of learning, education and career can remove the obstacles of the mind for the groups directly related to the policy and better promote it. 
Every member of society should take this as their responsibility to pursue the progress of ideology, create a good social atmosphere and also add fresh air to their personal life; understand, believe and support the national decision to reduce resistance to China's education reform.

\section{Conclusion}

The combination of "double reduction" policy and ideological \& political education should make good use of the Internet platform and new media technology, fully mobilize resources, strengthen the monitoring of public opinion, grasp the guidance of public opinion, and do a good job of positive propaganda. On the basis of understanding "why can be combined", grasp "for whom to combine", and constantly explore "how to combine", so that the two can promote each other and complement each other.

\section{References}

[1] Long B. The proliferation mechanism of academic burden in primary and secondary schools and the way to cure it: the limit and the increase of energy of the policy of "double reduction"[J]. Nanjing Social Science, 2021,(10):146-155.

[2] Xiong B. The implementation of "double reduction" must gnaw down two "hard bones" [J]. Beijing Observation, 2021,(09):33.

[3] Zhang Z. Reconstruction and governance of public education system under the pattern of "double reduction" [J]. China Journal of Education,2021,(09):20-26,49.

[4] Shi X. Analysis of strategies for Civics teachers to cultivate students' career outlook [J]. Journal of Jincheng Vocational and Technical College,2021,(14):43-45.

[5] Li W. Leading students' growth with a correct view of interests[J]. Reference of political teaching in secondary schools,2021,(03):87-88.

[6] $\mathrm{Yu} \mathrm{Y}$. Analysis of the important and difficult points in the part of life view in the class of "ideology, morality and rule of law" [J]. Thought Education Research,2021,(08):114-119.

[7] You L. The "double reduction" work on the ground "combination fist" [J]. China Ethnic Education, 2021,(10):46-47. 